\title{
G

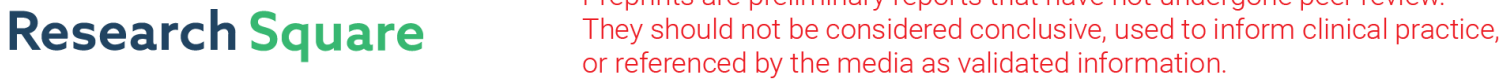 \\ Incidental Findings on Whole-body Computed Tomography in Major Trauma Patients: Who and What?
}

\section{Ping-Yuan Liu}

Chang Gung Memorial Hospital Linkou Main Branch: Chang Gung Memorial Hospital

\section{Ling-Wei Kuo}

Chang Gung Memorial Hospital Linkou Main Branch: Chang Gung Memorial Hospital

\section{Chien-Hung Liao}

Chang Gung Memorial Hospital Linkou Main Branch: Chang Gung Memorial Hospital

\section{Chi-Hsun Hsieh}

Chang Gung Memorial Hospital Linkou Main Branch: Chang Gung Memorial Hospital

\section{Francesco Bajani}

Chang Gung Memorial Hospital Linkou Main Branch: Chang Gung Memorial Hospital

\section{Chih-Yuan Fu ( $\nabla$ drfu5564@gmail.com )}

Department of Trauma and Emergency Surgery, Chang Gung Memorial Hospital 5, Fu-Hsing Street, Kwei Shan Township, Taoyuan, Taiwan

\section{Research article}

Keywords: whole-body computed tomography, nontraumatic findings, major trauma

Posted Date: November 5th, 2020

DOl: https://doi.org/10.21203/rs.3.rs-96067/v1

License: (c) (i) This work is licensed under a Creative Commons Attribution 4.0 International License.

Read Full License

Version of Record: A version of this preprint was published at The American Surgeon on February 26th, 2021. See the published version at https://doi.org/10.1177/0003134821998685. 


\section{Abstract}

\section{Background}

The use of whole-body computed tomography (WBCT) scans has greatly increased in the management of patients with major trauma. Sometimes, nontraumatic findings on WBCT are observed. In the current study, we aimed to investigate the proportion of nontraumatic findings on WBCT in major trauma patients and the characteristics of patients with nontraumatic findings on WBCT.

\section{Methods}

From June 2013 to May 2016, adult trauma patients who received WBCT were enrolled. The proportions of nontraumatic findings in different anatomical regions were studied. Nontraumatic findings were classified and evaluated as clinically important findings and findings that did not need further follow-up or treatment. The characteristics of patients with nontraumatic findings were analyzed and compared with those of patients without nontraumatic findings.

\section{Results}

A total of 217 patients were enrolled in this study during the 3-year study period, and $89(41.0 \%)$ patients had nontraumatic findings. Nontraumatic findings were found more frequently in the abdomen $(69.2 \%)$ than in the head/neck (17.3\%) and chest regions (13.5\%). In total, $31.3 \%$ of the findings needed further follow-up or treatment. Patients with nontraumatic findings that needed further management were significantly older than patients without nontraumatic findings ( 57.3 vs. $38.9, p<0.001$ ), especially those with abdominal nontraumatic findings ( 57.9 vs. $41.3, p<0.001)$. A significantly higher proportion of females was observed in the group with head/neck nontraumatic findings that needed further management than in the group without nontraumatic findings ( $56.3 \%$ vs. $24.9 \%, p=0.015)$.

\section{Conclusions}

WBCT could provide alternative benefits for nontraumatic findings. The WBCT images should be read carefully for nontraumatic findings, especially for elderly patients. For female patients, the head/neck region should be carefully evaluated with WBCT for possible thyroid lesions. A comprehensive program for the follow-up of nontraumatic findings is needed.

\section{Background}

With the advent of spiral computed tomography and multislice scanning techniques, the use of wholebody computed tomography (WBCT) scans has greatly increased over the last decades, and this method has become a standard imaging modality in the management of patients with major trauma due to its high diagnostic yield and wide availability. ${ }^{1-4}$ A quick and complete overview of traumatic injuries in all relevant body regions (head to pelvis) can be performed with the technique. 
In addition to traumatic findings, nontraumatic findings on WBCT scans are occasionally observed. These incidental findings might be beneficial to patients, such as for earlier disease detection (e.g., malignancy). However, they may also result in a high degree of patient anxiety and extra medical costs for a series of additional examinations, and ultimately, the lesion might not affect the patient's health. Past studies have reported that the rate of nontraumatic findings on WBCT in trauma patients ranges from $31-54 \%$ and noted that those findings generally had poor follow-up rates. ${ }^{5-13}$

Therefore, we reported the proportion of nontraumatic findings on WBCT for major trauma patients at our institution. The characteristics of patients with nontraumatic findings on WBCT were evaluated. This information will help physicians improve care by modifying the interpretation of WBCT images and maintaining a higher index of suspicion for nontraumatic findings.

\section{Methods}

From June 2013 to May 2016, we retrospectively reviewed the Chang Gung Memorial Hospital (CGMH) trauma patient registry and medical records. $\mathrm{CGMH}$ is a level I trauma referral center with more than 3,000 beds and serves a population of more than $5,000,000$ people in adjacent counties, and the emergency department (ED) treats more than 25,000 trauma patients annually. In our institution, a 64slice multidetector CT scanner is used to evaluate trauma patients. Additionally, the CT and resuscitation rooms are integrated in the same area of the ED. Patients with major trauma who received WBCT were the focus of our study during this $36-$ month investigational period.

Trauma patients in our ED were treated according to our established protocol, which was based on the advanced trauma life support (ATLS) guidelines. ${ }^{14}$ The trauma team was activated for patients with major trauma who were sent to our ED. In addition to general resuscitation and evaluation, WBCT was performed for a comprehensive and rapid survey. The criteria for major trauma at our institution include (1) systolic blood pressure < 90 mmHg; (2) Glasgow Coma Scale score < 14; (3) visible injury in more than 2 body regions; (4) high-risk mechanism of injury (1. falls $>5$ meters ( 16.5 feet), 2 . high-speed motor vehicle accident, 3. ejection from vehicle, 4 . high-speed motor vehicle collision, 5 . pedestrian, bicyclist, or motorcyclist vs. vehicle $>30 \mathrm{kph}(18 \mathrm{mph}), 6$. fatality in same vehicle) ${ }^{14}$; and (5) other reasons for a WBCT scan judged by the first-line trauma surgeon. (Per our previous report, hypotension was not a contraindication for a CT scan with a short transportation distance and short scanning time.)

In the current study, patients with major trauma who received a WBCT examination were studied. Patients who were younger than 18 years old, were too unstable to receive WBCT or experienced out-of-hospital cardiac arrest, failed to respond to resuscitation and subsequently died in the ED without further treatment were excluded.

The WBCT protocol included an unenhanced scan of the head and neck, followed by a contrast-enhanced scan of the thorax, abdomen and pelvis with a scanning range from the apex of the thoracic cage to approximately $5 \mathrm{~cm}$ below the symphysis. The contrast-enhanced scan was acquired after unenhanced 
head and neck computed tomography was performed. A bolus of iohexol $(100 \mathrm{ml}$; Omnipaque $300 \mathrm{mg} / \mathrm{ml}$ ) was given as a continuous infusion at $3 \mathrm{ml} / \mathrm{s}$. The thorax, abdomen and pelvis were imaged after a delay of $70 \mathrm{~s}$ to acquire the postintravenous contrast images. The acquired axial images and the routinely generated sagittal and coronal reconstructions were stored in and accessed with the picture archiving and communication system.

After the WBCT data were uploaded, the radiologic images were read by both a first-line trauma surgeon and a senior radiologist with expertise in trauma. The written radiologist interpretations of the WBCT examinations were reviewed for documented nontraumatic findings. Nontraumatic findings were defined as findings unrelated to the trauma. The investigator also checked the pictures and determined the presence of nontraumatic findings in the radiology report. If the nature of a finding (traumatic or nontraumatic) was not obvious on the image, the unblinded investigator would check the radiologic film and medical records during the ED stay and hospitalization. The patient files, further imaging studies and discharge diagnosis were reviewed to determine whether the finding was triggered by the current trauma. The medical charts during hospitalization and after discharge were also collected to evaluate the clinical consequences and follow-up outcomes.

In contrast to the complicated classifications that were previously published, in the current study, the nontraumatic findings were categorized into two groups according to clinical importance and severity. ${ }^{13}$ One group included findings that did not require intervention or further examination, and the other group included findings that were clinically significant and should be managed further (treatment or follow-up). Patients with findings that were potentially severe and required immediate intervention are reported in detail separately.

In the present study, nominal data are presented as a percentage and were compared using Fisher's exact test, whereas numerical data are presented as the mean and standard deviation and were compared using the independent sample t-test and one-way analysis of variance test. All statistical analyses were performed using the SPSS software package (version 24.0). A $p<0.05$ was considered statistically significant.

\section{Results}

During the 36-month study period, 229 major trauma patients were admitted to our ED with a WBCT scan. Twelve patients were excluded from the study for being younger than 18 years of age or having incomplete hospitalization documents or incomplete studies. Therefore, a total of 217 patients with a mean age of $44.6 \pm 18.4$ were enrolled in the study. Of these patients, 158 were male $(72.8 \%)$, and 59 were female (27.2\%). The mean injury severity score (ISS) was $26.3 \pm 12.3$, and the mean hospitalization duration was $17.8 \pm 14.7$ days (Table 1 ). The most common mechanisms of injury were traffic accidents $(140 / 217,64.5 \%)$ and falling down $(58 / 217,26.7 \%)$. 
Table 1

Demographics, trauma mechanisms and outcomes of patients who underwent WBCT in the current study $(\mathrm{N}=217)$

\begin{tabular}{|c|c|c|}
\hline & Numbers & $\mathrm{SD}^{\#}$ or percentage $(\%)$ \\
\hline Age & $44.6(18-94)$ & 18.4 \\
\hline \multicolumn{3}{|l|}{ Sex } \\
\hline Male & 158 & $72.8 \%$ \\
\hline Female & 59 & $27.2 \%$ \\
\hline ISS & $26.3(1-75)$ & 12.3 \\
\hline \multicolumn{3}{|l|}{ Outcome } \\
\hline Death & 52 & $24.0 \%$ \\
\hline Recovered and discharged & 143 & $65.9 \%$ \\
\hline Transferred & 15 & $6.9 \%$ \\
\hline Discharged against medical advice & 7 & $3.2 \%$ \\
\hline Hospitalization length & $17.76(0-69)$ & 14.658 \\
\hline \multicolumn{3}{|c|}{ WBCT = whole-body computed tomography } \\
\hline \multicolumn{3}{|l|}{ ISS = injury severity score } \\
\hline \multicolumn{3}{|l|}{$\mathrm{SD}=$ standard deviation } \\
\hline \multicolumn{3}{|c|}{ \# Numerical data: mean (range) with SD } \\
\hline \$ Nominal data: $\mathrm{N}$ (percentage) & & \\
\hline
\end{tabular}

In the present study, $96.3 \%(209 / 217)$ of the patients had trauma-related findings, and $41 \%(89 / 217)$ had nontraumatic findings. The proportions of nontraumatic findings in the head/neck, chest and abdomen were 10.6\% (23/217), 7.8\% (17/217) and 31.4\% (66/217), respectively (Table 2). Among the 89 patients with nontraumatic findings, 133 findings were recorded. The distribution of these nontraumatic findings is listed in Table 3 by anatomic region. Diagnoses that were "clinically important and might need followup" or in "no need of follow-up" are shown. Of the diagnoses that were clinically important, thyroid nodule(s) was the major nontraumatic finding of the head and neck (10/217, 4.6\%). In the chest region, the major nontraumatic findings were lung nodules $(6 / 217,2.8 \%)$. In the abdominal region, spine spondylosis $(14 / 217,6.5 \%)$, gallbladder stones $(13 / 217,6.0 \%)$, and renal stones $(7 / 217,3.2 \%)$ were the top three nontraumatic findings that were clinically important. 


\begin{tabular}{|lll|}
\hline \multicolumn{2}{|l|}{ Table 2. WBCT results of all patients (298 diagnoses in 217 patients) } \\
\hline Patient number & Numbers & Percentage \\
\hline Patients with trauma-related findings & 209 & $96.3 \%(209 / 217)$ \\
\hline Patients with nontraumatic findings & 89 & $41.0 \%(89 / 217)$ \\
\hline Head and neck & 23 & $10.6 \%(23 / 217)$ \\
\hline Chest & 17 & $7.8 \%(17 / 217)$ \\
\hline Abdomen & 66 & $31.4 \%(66 / 217)$ \\
\hline Diagnosis number (133 nontraumatic findings) & & \\
\hline Head and neck & 23 & $17.3 \%(23 / 133)$ \\
\hline Chest & 18 & $13.5 \%(18 / 133)$ \\
\hline Abdomen & 92 & $69.2 \%(92 / 133)$ \\
\hline
\end{tabular}

WBCT =whole-body computed tomography

Patients may have both trauma-related findings and nontraumatic findings, and each patient could have had more than one nontraumatic finding. Thus, the total number of diagnoses exceeds the total number of patients. 
Table 3

Nontraumatic findings of 217 patients (by anatomical location)

\begin{tabular}{|c|c|c|c|}
\hline Head and neck & & Abdomen/pelvis & \\
\hline Thyroid nodule & 10 & Renal cyst & 20 \\
\hline 5th, 6th ventricle & 2 & Spine spondylosis & 14 \\
\hline Arachnoid cyst & 2 & Gallstone & 13 \\
\hline Porencephaly & 1 & Hepatic cyst & 11 \\
\hline Maxillary sinus polyp & 1 & Renal stone & 7 \\
\hline C-spine degenerative disease & 7 & Liver nodule & 5 \\
\hline Chest & & Colon diverticulum & 4 \\
\hline Lung nodule & 6 & Polycystic disease & 4 \\
\hline Pulmonary bullae & 2 & Inguinal hernia & 3 \\
\hline Esophageal diverticulum & 2 & Adrenal gland tumor & 3 \\
\hline Clavicle bone cyst & 1 & Vertebral body deformity & 2 \\
\hline Chronic aortic dissection & 1 & Prostate tumor & 2 \\
\hline Hiatal hernia & 1 & Liver hemangioma & 2 \\
\hline Kommerell diverticulum & 1 & Adrenal gland cyst & 1 \\
\hline Rib pseudarthrosis & 1 & Left adnexal teratoma & 1 \\
\hline Aberrant subclavian artery & 1 & Hydronephrosis & 1 \\
\hline \multirow[t]{4}{*}{ Vertebral hemangioma } & 1 & Pancreatic tumor & 1 \\
\hline & & Common bile duct tumor & 1 \\
\hline & & Lumbar lipoma & 1 \\
\hline & & Ovarian cyst & 1 \\
\hline
\end{tabular}

Table 4 shows the comparisons between patients with and without nontraumatic findings that needed further follow-up or treatment. Patients with nontraumatic findings that needed further management were significantly older than patients without nontraumatic findings that needed further management ( $57.3 \mathrm{vs.}$ $38.9, p<0.001$ ) (whole-body). When these nontraumatic findings were analyzed by different anatomical regions, age was not significantly different between these two groups in the head/neck or chest region subanalyses. However, patients with abdominal nontraumatic findings that needed further management were significantly older than patients without abdominal nontraumatic findings that needed further 
management ( 57.9 vs. $41.3, p<0.001)$. Furthermore, people who were 65 years old or older tended to be more likely to have nontraumatic findings that needed further management, both in the entire body and in the abdominal region. Similar comparisons were performed for sex between these two groups. The group with head/neck nontraumatic findings that needed further management had a significantly higher proportion of females than that without head/neck abdominal nontraumatic findings that needed further management $(56.3 \%$ vs. $24.9 \%, p=0.015)$. 
Table 4

Comparisons of age between patients with and without nontraumatic findings on WBCT who needed further treatment

\section{Age of patients}

\begin{tabular}{llll} 
& $\begin{array}{l}\text { Nontraumatic findings on WBCT } \\
\text { that needed } \\
\text { further management }(+)\end{array}$ & $\begin{array}{l}\text { Nontraumatic findings on WBCT that } \\
\text { needed } \\
\text { further management }(-)\end{array}$ & $\begin{array}{l}\text { p- } \\
\text { value* }\end{array}$ \\
$\begin{array}{l}\text { Whole } \\
\text { body }\end{array}$ & $68(57.3 \pm 16.3)$ & $149(38.9 \pm 16.4)$ & \\
\hline Anatomical body regions & & 0.001 \\
\hline Head/neck & $16(52.1 \pm 17.6)$ & $201(44.0 \pm 18.4)$ & 0.091 \\
\hline Chest & $12(53.3 \pm 12.1)$ & $205(44.1 \pm 18.6)$ & 0.096 \\
\hline Abdomen & $43(57.9 \pm 16.6)$ & $174(41.3 \pm 17.4)$ & $<$ \\
\end{tabular}

Proportion of elderly patients $\$$

Nontraumatic findings on WBCT that needed

further management (+)

Whole $\quad 15 / 68(22.1 \%)$

body

Anatomical body regions

Head/neck $3 / 16(18.8 \%)$

$1 / 12(8.3 \%)$

$11 / 43(25.6 \%)$

Proportion of females

Nontraumatic findings on WBCT that needed

further management (+)
Nontraumatic findings on WBCT that needed

pvalue\# further management (-)

$11 / 149(7.4 \%)$

0.002

\begin{tabular}{llll} 
Chest & $1 / 12(8.3 \%)$ & $25 / 205(12.2 \%)$ & 0.689 \\
Abdomen & $11 / 43(25.6 \%)$ & $15 / 174(8.6 \%)$ & 0.003 \\
\hline & $\begin{array}{l}\text { Proportion of females } \\
\text { Nontraumatic findings on WBCT } \\
\text { that needed } \\
\text { further management (+) }\end{array}$ & $\begin{array}{l}\text { Nontraumatic findings on WBCT that } \\
\text { needed } \\
\text { further management }(-)\end{array}$ & $\begin{array}{l}\text { p- } \\
\text { value\# }\end{array}$ \\
& &
\end{tabular}

WBCT = whole-body computed tomography

* Student's t-test, patient number (mean age \pm standard deviation)

\# Chi-square test, number of females/total number of patients (proportion of females)

$\$$ An elderly patient is defined as a patient 65 years old or older 


\begin{tabular}{|c|c|c|c|}
\hline \multicolumn{4}{|c|}{ Age of patients } \\
\hline $\begin{array}{l}\text { Whole } \\
\text { body }\end{array}$ & 19/68 (27.9\%) & $40 / 149(26.8 \%)$ & 0.866 \\
\hline \multicolumn{4}{|c|}{ Anatomical body regions } \\
\hline Head/neck & $9 / 16(56.3 \%)$ & $50 / 201(24.9 \%)$ & 0.015 \\
\hline Chest & $3 / 12(25.0 \%)$ & $56 / 205(27.3 \%)$ & 0.861 \\
\hline Abdomen & 9/43 (20.9\%) & $50 / 174(28.7 \%)$ & 0.344 \\
\hline \multicolumn{4}{|c|}{ WBCT $=$ whole-body computed tomography } \\
\hline \multicolumn{4}{|c|}{ * Student's t-test, patient number (mean age \pm standard deviation) } \\
\hline \multicolumn{4}{|c|}{ \# Chi-square test, number of females/total number of patients (proportion of females) } \\
\hline \$ An elderly & tient is definec & or older & \\
\hline
\end{tabular}

There were six patients with severe findings that required immediate evaluation and treatment (chronic type B aortic dissection, left intrahepatic duct intraductal papillary mucinous neoplasm, thyroid cancer, bilateral hydronephrosis, and porencephaly with midline shift of brain and left adrenal gland tumor); these data are shown in Table 5. 
Patients with potentially severe nontraumatic findings $(\mathrm{N}=6)$

\begin{tabular}{|c|c|c|c|}
\hline $\begin{array}{l}\text { Basic } \\
\text { data }\end{array}$ & Findings from WBCT & Diagnosis & Intervention \\
\hline $\begin{array}{l}50- \\
\text { year- } \\
\text { old } \\
\text { male }\end{array}$ & $\begin{array}{l}\text { Type B aortic dissection with extension into the } \\
\text { left common iliac artery with a mural thrombus at } \\
\text { a false lumen\# }\end{array}$ & $\begin{array}{l}\text { Chronic type B aortic } \\
\text { dissection }\end{array}$ & $\begin{array}{l}\text { TEVAR* } \\
\text { after } 10 \\
\text { days }\end{array}$ \\
\hline $\begin{array}{l}57- \\
\text { year- } \\
\text { old } \\
\text { female }\end{array}$ & $\begin{array}{l}\text { Distal } \mathrm{CBD}^{+} \text {obstruction with biliary dilatation and } \\
\text { atrophy of the left lobe of the liver }\end{array}$ & $\begin{array}{l}\text { Left intrahepatic duct } \\
\text { IPMN with biliary } \\
\text { obstruction }\end{array}$ & $\begin{array}{l}\text { MRCP\$ } \\
\text { after } 3 \\
\text { months }\end{array}$ \\
\hline $\begin{array}{l}60- \\
\text { year- } \\
\text { old } \\
\text { female }\end{array}$ & $\begin{array}{l}\text { A large tumor with central cystic changes in the } \\
\text { right thyroid }\end{array}$ & Thyroid cancer & $\begin{array}{l}\text { Lost to } \\
\text { follow-up }\end{array}$ \\
\hline $\begin{array}{l}80- \\
\text { year- } \\
\text { old } \\
\text { male }\end{array}$ & $\begin{array}{l}\text { Benign prostate hyperplasia with bilateral } \\
\text { hydronephrosis }\end{array}$ & Results of WBCT & $\begin{array}{l}\text { Lost to } \\
\text { follow-up }\end{array}$ \\
\hline \multirow{2}{*}{$\begin{array}{l}31- \\
\text { year- } \\
\text { old } \\
\text { female }\end{array}$} & $\begin{array}{l}\text { 1. Large cystic porencephaly }(8 \mathrm{~cm}) \text { on the medial } \\
\text { side of the left frontal lobe }\end{array}$ & \multirow[t]{2}{*}{$\begin{array}{l}\text { Porencephaly with } \\
\text { midline shift }\end{array}$} & \multirow[t]{2}{*}{$\begin{array}{l}\text { Lost to } \\
\text { follow-up }\end{array}$} \\
\hline & $\begin{array}{l}\text { 2. Midline shift of the brain due to the mass effect } \\
\text { of the above lesion }\end{array}$ & & \\
\hline $\begin{array}{l}51- \\
\text { year- } \\
\text { old } \\
\text { male }\end{array}$ & A left adrenal tumor $(4.6 \mathrm{~cm})$ & Results of WBCT & $\begin{array}{l}\text { Trauma- } \\
\text { related } \\
\text { mortality }\end{array}$ \\
\hline \multicolumn{4}{|c|}{ WBCT = whole-body computed tomography } \\
\hline \multicolumn{4}{|c|}{$\#$ = Stanford type B aortic dissection } \\
\hline \multicolumn{4}{|c|}{ *TEVAR = thoracic endovascular aortic repair } \\
\hline \multicolumn{4}{|c|}{$+\mathrm{CBD}=$ common bile duct } \\
\hline
\end{tabular}

\section{Discussion}

WBCT has been used frequently for major trauma patients worldwide. In addition to traumatic findings that require immediate management, Sierink et al. reported an incidental finding rate of $44.5 \%(143 / 321)$ with traumatic WBCT in $2013 .{ }^{5}$ Seah et al. also showed that $57 / 104$ trauma patients (54.8\%) had incidental findings identified on the WBCT radiologist report. ${ }^{6}$ Overall, the incidental finding rate in the previous literature ranged from 31 to $54 \% .{ }^{5-13}$ The results of the current study are consistent with those 
of previous studies $(89 / 217,41.0 \%)$. However, owing to the critical condition of trauma patients who require WBCT, the images are usually read for traumatic findings. Thus, nontraumatic findings may be overlooked by first-line trauma surgeons or ED physicians. Some of these nontraumatic findings could be life-threatening or require further evaluation and treatment. The nontraumatic findings on WBCT for trauma patients generally have poor follow-up rates. ${ }^{5,6,9,10,15,16}$

Although it is difficult to identify and treat all WBCT findings, a comprehensive interpretation and followup plan is important for such nontraumatic findings. However, the distribution of nontraumatic findings is diverse among body regions and patients (Table 3). Some findings indicate an immediate need for treatment, some indicate close follow-up or continuous monitoring, some could not be identified by the primary imaging examination and needed further examinations, and some are harmless and do not indicate the need for any intervention. Patients might benefit from an early diagnosis of malignancies; on the other hand, these findings may increase anxiety and create extra medical costs for a series of additional examinations, and ultimately, the lesion might not affect the patient's health. The fundamental and perhaps most important question is which patients have a higher probability of having nontraumatic findings that may indicate the need for early treatment?

Compared with patients without nontraumatic findings, patients with nontraumatic findings were significantly older ( 57.3 vs. $38.9, p<0.001)$. This aging effect is especially significant for findings in the abdomen ( 57.9 vs. $41.3, p<0.001)$. In addition to several intra-abdominal malignancies, gallstone disease is one of the leading causes of digestion-related hospital admissions for elderly patients. ${ }^{17,18}$ The frequency of gallstone disease varies among different countries and ethnic populations as well as various regions of each country. ${ }^{19}$ In most developed countries, the overall prevalence of gallstone disease has been reported to be between $10 \%$ and $20 \%{ }^{20,21}$ Furthermore, previous studies have shown that the occurrence of gallstone disease increases with age, with a high prevalence rate at 50-60 years in both men and women. ${ }^{21-25}$ Renal stones are also a common disease with a significant healthcare burden worldwide. Epidemiological studies show that the prevalence rate ranges between $4 \%$ and $20 \%$ in developed countries. ${ }^{26-27}$ In Taiwan, the prevalence of upper urinary tract stones has been reported to range from $2.85-9.6 \% .{ }^{28-30} \mathrm{Age}$ is a risk factor for urolithiasis, especially in people who are $50-60$ years old. ${ }^{31-34}$ Nontraumatic findings are significantly more common in patients older than 40 years of age, as reported by previous studies. ${ }^{10,15}$ As the average age of the modern population continues to increase and a corresponding increase in the average age of injured patients occurs, nontraumatic findings will become even more common and a greater patient-care and medical-legal dilemma. Therefore, more attention should be paid to the interpretation of WBCT images of elderly patients. Furthermore, an alert notification system for important incidental findings on WBCT may be needed. Even after admission, most physicians focus on a patient's traumatic findings and treat the major problems first. Some incidental findings noted on the WBCT performed prior to admission could be overlooked, causing patients to lose the clinical benefit. It was reported that an alert notification of critical test results improved patient care ${ }^{35,36}$. The implementation of a similar system for the interpretation of incidental findings on WBCT could be feasible and beneficial. 
Another point of interest is that female patients had more important nontraumatic findings in the head and neck than male patients $(15.0 \%$ vs. $4.0 \%, p=0.015)$. Among the 10 patients with thyroid nodules who were diagnosed incidentally with WBCT, 7 were female (11.9\%), and only 3 were male (1.9\%). Thyroid nodules are predominantly found in females. ${ }^{37-39}$ Although most thyroid nodules are benign, thyroid cancer occurs in 4 to $15 \%$ of patients with thyroid nodules. ${ }^{40-45}$ In the current guidelines, it is suggested that people with thyroid nodules receive follow-up care. ${ }^{46}$ These findings suggest that WBCT images of the head and neck regions should be read carefully for females.

Approximately $2.8 \%(6 / 217)$ of patients had nontraumatic findings that were potentially severe and needed further follow-up. Chronic aortic dissection (Stanford type B) was diagnosed incidentally with WBCT in a patient with a traumatic brain injury. After his trauma was treated, a thoracic endovascular aortic repair procedure was performed smoothly. There was one patient with abrupt tapering of the distal common bile duct and atrophy of the left liver on WBCT. This nontraumatic finding was recorded on the medical chart, and magnetic resonance imaging was performed accordingly by an outpatient department physician after discharge. Then, an intraductal papillary mucinous neoplasm with biliary obstruction was diagnosed. Except for the above two patients, the other patients had no follow-up records of potentially severe incidental findings, even after discharge. ED physicians or trauma surgeons usually focus on patients' traumatic findings, so subacute lesions are overlooked. Prior literature has noted the poor followup of such nontraumatic findings in trauma patients. 5,6,9,10,15,16 In regard to the management of nontraumatic findings, a previous study has looked at the use of midlevel providers to perform tertiary trauma surveys once the patients are admitted and to notify those patients prior to discharge with appropriate follow-up plans. ${ }^{16}$ Another study implemented a dedicated incidental finding coordinator for the detection and follow-up of nontraumatic findings, which resulted in a more than 2.5 -fold higher rate for the identification of incidental findings and adequate follow-up both in the hospital and after discharge. ${ }^{15}$ This seems to represent a potential solution to this patient-care and medical-legal dilemma in the future. This approach will rely on collaborative efforts between radiologists, trauma and emergency physicians, and primary care physicians. Primary care physicians should value those nontraumatic findings more and arrange examinations, interventions or outpatient department follow-up examinations when the patients are discharged from the ward. More immediately, however, front-line trauma staff need to be vigilant about discussing the nontraumatic findings with their discharged patients to ensure that all patients have appropriate follow-up care arranged.

The limitations of this study include its retrospective nature and limited patient sample from a single institution. Although there are a large number of trauma patients in our ED per year, only a small proportion of patients with major trauma were enrolled in the current study. Thus, possible selection bias may have limited our conclusions. The WBCT protocol was designed for trauma patients. Therefore, the images of the head and neck were non-contrast enhanced. Under this condition, some lesions that need contrast enhancement for diagnosis could not be detected. In addition, the general use of WBCT for all trauma patients is infeasible because of biohazards of radiation exposure and expanded medical cost. Another concern is that some findings were difficult to define, making it challenging to determine whether

Page $13 / 18$ 
they should be included in this study. For example, spinal degenerative changes were only reported in severe cases that could be observed on imaging. A reporting threshold might be needed for minor cases. Further studies with larger sample sizes and prospective designs are needed to establish an accurate interpretation system for a comprehensive evaluation of both traumatic findings and nontraumatic findings.

\section{Conclusions}

WBCT could provide alternative benefits for nontraumatic findings. WBCT images should be read carefully for nontraumatic findings, especially for elderly patients. For female patients, the head/neck region of the WBCT scan should be evaluated carefully for possible thyroid lesions. A comprehensive program for the follow-up of nontraumatic findings is needed.

\section{Declarations}

Ethical Approval and Consent to participate: This retrospective study was approved by the Institutional of Review Board of Chang Gung Memorial Hospital

Consent for publication: All authors agree with the publication of this article

Funding: No commercial associations with or sources of support from any funding agency

Conflicts of interest/Competing interests: The authors have no commercial associations or sources of support that might pose a conflict of interest.

Availability of data and material: Not applicable.

Code availability: Not applicable.

\section{Authors' contributions:}

Study conception and design: Liu, Kuo and Fu

Acquisition of the data: Liu, Kuo,,$\underline{\text { Fu, Liao, and Hsieh }}$

Analysis and interpretation of the data: Liu and Fu

Drafting of the manuscript: Liu

Critical revision: Kuo and Bajani

Acknowledgements: Not applicable

\section{References}


1. Albrecht T, Stahel P, Ertel W, Wolf K. The role of whole body spiral CT in the primary work-up of polytrauma patients--comparison with conventional radiography and abdominal sonography . RoFo: Fortschritte auf dem Gebiete der Rontgenstrahlen und der Nuklearmedizin, 2004;176:1142-50.

2. TraumaRegister DGU. 20 years of trauma documentation in Germany-actual trends and developments. Injury, 2014;45:S14-9.

3. Huber-Wagner S, Lefering R, Qvick L-M, Körner M, Kay MV, Pfeifer K-J, et al. Working Group on Polytrauma of the German Trauma Society. Effect of whole-body CT during trauma resuscitation on survival: a retrospective, multicentre study. The Lancet, 2009;373:1455-61.

4. Healy DA, Hegarty A, Feeley I, Clarke-Moloney M, Grace PA, Walsh SR.Systematic review and metaanalysis of routine total body CT compared with selective CT in trauma patients. Emerg Med J, 2013;31:101-8

5. Sierink JD, Saltzherr TD, Russchen MD, Castro SD, Beenen LD, Schep ND, et al. Incidental findings on total-body CT scans in trauma patients. Injury, 2014;45:840-4.

6. Seah MK, Murphy CG, Mcdonald S, Carrothers A.Incidental findings on whole-body trauma computed tomography: Experience at a major trauma centre. Injury, 2016;47:691-4.

7. Treskes K, Bos SA, Beenen LFM, Sierink JC, Edwards MJR, Beuker BJA, et al. High rates of clinically relevant incidental findings by total-body CT scanning in trauma patients; results of the REACT-2 trial. European radiology, 2017;27:2451-62.

8. Smith CM, Mason S. The use of whole-body CT for trauma patients: survey of UK emergency departments. Emerg Med J, 2012;29:630-4.

9. Munk M-D, Peitzman AB, Hostler DP, Wolfson AB. Frequency and follow-up of incidental findings on trauma computed tomography scans: experience at a level one trauma center. The Journal of emergency medicine, 2010;38:346-50.

10. Paluska TR, Sise MJ, Sack DI, Sise CB, Egan MC, Biondi M. Incidental CT findings in trauma patients: incidence and implications for care of the injured. Journal of Trauma and Acute Care Surgery, 2007;62:157-61.

11. Hoffstetter P, Herold T, Daneschnejad M, Zorger N, Jung EM, Feuerbach S, et al. Non-traumaassociated additional findings in whole-body CT examinations in patients with multiple trauma. RoFo: Fortschritte auf dem Gebiete der Rontgenstrahlen und der Nuklearmedizin, 2008;180:120-6.

12. Fakler JK, Özkurtul O, Josten C. Retrospective analysis of incidental non-trauma associated findings in severely injured patients identified by whole-body spiral CT scans. Patient safety in surgery, 2014;8:36.

13. Kroczek EK, Wieners G, Steffen I, Lindner T, Streitparth F, Hamm B, et al. Non-traumatic incidental findings in patients undergoing whole-body computed tomography at initial emergency admission. Emerg Med J, 2017;34:643-6.

14. American College of Surgeons, Committee on Trauma. Advanced Trauma Life Support. 10th ed. Chicago, IL: American College of Surgeons; 2018. 
15. Sperry JL, Massaro MS, Collage RD, Nicholas DH, Forsythe RM, Watson GA, et al. Incidental radiographic findings after injury: dedicated attention results in improved capture, documentation, and management. Surgery, 2010;148:618-24.

16. Huynh TT, Moran KR, Blackburn AH, Jacobs DG, Thomason MH, Sing RF. Optimal management strategy for incidental findings in trauma patients: an initiative for midlevel providers. Journal of Trauma and Acute Care Surgery, 2008;65:331-6.

17. Tsai CJ, Leitzmann MF, Hu FB, Willett WC, Giovannucci ELA. prospective cohort study of nut consumption and the risk of gallstone disease in men. American Journal of epidemiology, 2004;160:961-8.

18. Henao-Morán S, Denova-Gutiérrez E, Morán S, Duque X, Gallegos-Carrillo K, Macías N, et al. Recreational physical activity is inversely associated with asymptomatic gallstones in adult Mexican women. Annals of hepatology, 2014;13:810-8.

19. Khan HN, Harrison M, Bassett E-E, Bates T. A 10-year follow-up of a longitudinal study of gallstone prevalence at necropsy in South East England. Digestive diseases and sciences, 2009;54:2736-41.

20. Hou L, Shu XO, Gao YT, Ji BT, Weiss JM, Yang G, et al. Anthropometric measurements, physical activity, and the risk of symptomatic gallstone disease in Chinese women. Annals of epidemiology, 2009;19:344-50.

21. Behari A, Kapoor VK. Asymptomatic Gallstones (AsGS)-To Treat or Not to?. Indian Journal of Surgery, 2012;74:4-12.

22. Shaffer EA. Epidemiology and risk factors for gallstone disease: has the paradigm changed in the 21st century?. Current gastroenterology reports, 2005;7:132-40.

23. Panpimanmas S, Manmee C. Risk factors for gallstone disease in a Thai population. Journal of epidemiology, 2009;19:116-21.

24. Kratzer W, Kachele V, Mason RA, Hill V, Hay B, Haug C, et al. Gallstone prevalence in Germany: the Ulm gallbladder stone study. Digestive diseases and sciences, 1998;43:1285-91.

25. Nakeeb A, Comuzzie AG, Martin L, Sonnenberg GE, Swartz-Basile D, Kissebah AH, et al. Gallstones: genetics versus environment. Annals of surgery, 2002;235:842.

26. Scales Jr CD, Smith AC, Hanley JM, Saigal CS, Urologic Diseases in America Project. Prevalence of kidney stones in the United States. European urology, 2012;62:160-5.

27. Trinchieri A. Epidemiology of urolithiasis. Archivio italiano di urologia, andrologia: organo ufficiale [di] Societa italiana di ecografia urologica e nefrologica, 1996;68:203-49.

28. Chen MH, Weng SF, Hsu CC, Lin HJ, Su SB, Wang JJ, et al. Urolithiasis risk: a comparison between healthcare providers and the general population. BMC health services research, 2016;16:273.

29. Huang WY, Chen YF, Carter S, Chang HC, Lan CF, Huang KH. Epidemiology of upper urinary tract stone disease in a Taiwanese population: a nationwide, population based study. The Journal of urology, 2013;189:2158-63. 
30. Lee YH, Huang WC, Tsai JY, Lu CM, Chen WC, Lee MH, et al. Epidemiological studies on the prevalence of upper urinary calculi in Taiwan. Urologia internationalis, 2002;68:172-7.

31. Trinchieri A. Epidemiology of urolithiasis: an update. Clinical cases in mineral and bone metabolism, 2008;5:101.

32. Taylor EN, Stampfer MJ, Curhan GC Obesity, weight gain, and the risk of kidney stones. Jama, 2005;293:455-62.

33. Curhan GC, Willett WC, Rimm EB, Stampfer MJ. A prospective study of dietary calcium and other nutrients and the risk of symptomatic kidney stones. New England Journal of Medicine, 1993;328:833-8.

34. Najem GR, Seebode JJ, Samady AJ, Feuerman M, Friedman L. Stressful life events and risk of symptomatic kidney stones. International journal of epidemiology, 1997;26:1017-23.

35. Tung EL, Dibble EH, Jindal G, Movson JS, Swenson DW. Survey of radiologists and emergency department providers after implementation of a global radiology report categorization system. Emergency Radiology, 2020;1-11.

36. LACSON, Ronilda, et al. Four-year impact of an alert notification system on closed-loop communication of critical test results. American Journal of Roentgenology, 2014;203.5:933-8.

37. Vander JB, Gaston EA, Dawber TR. The significance of nontoxic thyroid nodules: final report of a 15year study of the incidence of thyroid malignancy. Annals of internal medicine, 1968;69:537-40.

38. Ezzat S, Sarti DA, Cain DR, Braunstein GD. Thyroid incidentalomas: prevalence by palpation and ultrasonography. Archives of internal medicine, 1994;154:1838-40.

39. Brander A, Viikinkoski P, Nickels J, Kivisaari L. Thyroid gland: US screening in a random adult population. Radiology, 1991;181:683-7.

40. Werk EE, Vernon BM, Gonzalez JJ, Ungaro PC, McCoy RC. Cancer in thyroid nodules: a community hospital survey. Archives of internal medicine, 1984;144:474-6.

41. Belfiore A, Giuffrida D, La Rosa GL, Ippolito O, Russo G, Fiumara A, et al. High frequency of cancer in cold thyroid nodules occurring at young age. European Journal of Endocrinology, 1989;121:197-202.

42. Frates MC, Benson CB, Doubilet PM, Kunreuther E, Contreras M, Cibas ES, et al. Prevalence and distribution of carcinoma in patients with solitary and multiple thyroid nodules on sonography. The Journal of Clinical Endocrinology \& Metabolism, 2006;91:3411-7.

43. Hegedüs L. The thyroid nodule. New England Journal of Medicine, 2004;351:1764-71.

44. Lin JD, Chao TC, Huang BY, Chen ST, Chang HY, Hsueh C. Thyroid cancer in the thyroid nodules evaluated by ultrasonography and fine-needle aspiration cytology. Thyroid, 2005;15:708-17.

45. Kwong N, Medici M, Angell TE, Liu X, Marqusee E, Cibas ES, et al. The influence of patient age on thyroid nodule formation, multinodularity, and thyroid cancer risk. The Journal of Clinical Endocrinology \& Metabolism, 2015;100:4434-40.

46. Cooper DS, Doherty GM, Haugen BR, Kloos RT, Lee SL, Mandel SJ, et al. Management guidelines for patients with thyroid nodules and differentiated thyroid cancer: The American Thyroid Association 
Guidelines Taskforce. Thyroid, 2006;16:109-42.

Page 18/18 